\title{
əWind Direction Measurements on Moored Coastal Buoys
}

\author{
VLADO MALAČIČ \\ Marine Biology Station, National Institute of Biology, Piran, Slovenia
}

(Manuscript received 4 October 2018, in final form 16 March 2019)

\begin{abstract}
Wind direction measurements from anchored floating objects (buoys) are disturbed by the movement of an agitated sea surface. This article describes corrected wind direction measurements that account for a rotated and tilted anemometer, in which the rotations around the Euler angles "roll," "pitch," and "yaw" are simultaneously measured on coastal buoy "Vida" in Slovenian waters of the Gulf of Trieste. The wind data analysis is composed of a short-term analysis during a 4-h summer storm and a long-term analysis of wind direction for an 8-yr period. In the short-term analysis, the time evolution of the spectral composition of the anemometer's translation and wind speeds revealed the dominance of 3-4-s oscillations that are mostly caused by waves. Anemometer velocity may account for up to $5 \%$ of apparent wind speed. In the long-term analysis, wind direction measurements were validated against those from two other stations in the Gulf of Trieste, as well as from the Acqua Alta tower in front of the Venice lagoon; all three are located in Italian waters. Short-term analysis of a summer storm and long-term measurements from four stations show that correcting the wind direction with the buoy's orientation accounts for about $10^{\circ}-12^{\circ}$ of the error in wind direction.
\end{abstract}

\section{Introduction}

Wind measurements collected by anemometers mounted on floating objects are subjected to movements driven by the motion of the sea surface. Despite new technologies such as satellite synthetic-aperture radar (SAR) wind measurements (Lin et al. 2008) that enable the "sea state" determined by winds and waves to be followed, moored stations are still extremely valuable. The definition that separates the ocean or "offshore" buoys and coastal buoys in distinct categories is not clear, although one useful statement (Bosard and Sprigg 1998, p. 25) is that "the Coastal Marine Automated Network (C-MAN) stations help forecasters monitor unique localized conditions known to occur near coastal promontories and extending 5-10 km offshore.” Deploying ocean or offshore buoys is more difficult, more expensive, and less feasible than deploying coastal buoys; therefore, the latter are much more numerous than ocean buoys. A worldwide list of coastal moored buoys does not seem to exist. Joint World Meteorological

ə Denotes content that is immediately available upon publication as open access.

Corresponding author: Vlado Malačič, vlado.malacic@nib.si
Organization/Intergovernmental Oceanographic Commission (WMO/IOC) Technical Commission for Oceanography and Marine Meteorology (JCOMM) monitors oceanic buoys (http://www.jcommops.org), as does OceanSITES (http://www.oceansites.org/). In 2016, there appeared to be 92 ocean buoys that measured winds (with two anemometers) by gauging the vertical flux of momentum (J. Karstensen 2017, private communication). The United Kingdom's network of moored buoys around England is composed of over 30 moored buoys, 12 of which yield online data about wind direction and speed (http://www.scottishweather.net/wxbuoys.php). The Mediterranean Oceanography Network for the Global Ocean Observing System (MONGOOS) comprises coastal (land and offshore) stations, more than 30 of which are moored buoys that measure wind direction and speed (http://www.mongoos.eu/in-situ-and-forecasts). Coastal buoy "Vida," located in Slovenian waters of the Gulf of Trieste, is part of the MONGOOS measurement network. Numerous buoys that measure wind are also commissioned by private entities (often oil and gas companies), which are not usually members of any observing network.

Wind statistics for the Gulf of Trieste measured by buoy Vida's predecessor showed that the east-northeast bora wind was the most dominant (Jeromel et al. 2009) 


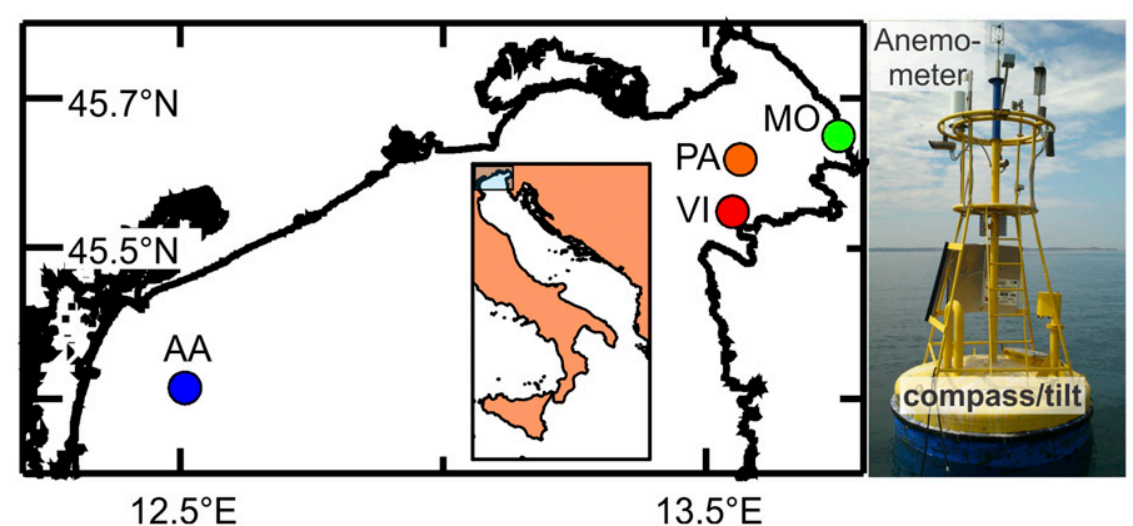

FIG. 1. (left) Locations of the Acqua Alta (AA) tower $16 \mathrm{~km}$ east of the Venice coastline (Italy), offshore pillar Paloma (PA; Italy), shoreline meteorological station Molo Fratelli Bandiera (MO) in Trieste, and coastal buoy Vida (VI; Slovenia). (right) External appearance of buoy Vida. The compass/tilt sensor is placed inside the buoy's hull, just below the mast. The anemometer is the topmost device on Vida at a height of $5 \mathrm{~m}$.

and the sirocco or southern wind was the secondmost-dominant. Measurements of wind and currents also validated forecast models for the atmosphere and ocean (Malačič et al. 2012). Buoy measurements of surface currents and winds revealed by high-frequency (HF) radar measurements also supported findings of the Gulf of Trieste's surface circulation (Cosoli et al. 2013). Measurements of currents and (especially) winds at buoy Vida's location are also important for understanding the circulation of the northern Adriatic Sea (Dorman et al. 2007; Malačič et al. 2012; Ramšak et al. 2013). It was found, for example, that the dominant bora wind in the northernmost part of the Adriatic blows with roughly "undiminished" speed from the open part of the Gulf of Trieste (measured at Vida) toward Venice, as measured at the Acqua Alta platform (Dorman et al. 2007).

Given their utility, an in-depth analysis of wind measurements from buoy Vida is constructive. Measurement devices and their functions will be described in the methods section, together with the methodologies used for the short- and long-term wind measurement analyses. The results section will analyze wind speed and direction (where the latter is linked to the buoy's orientation) for a 4-h summer storm, along with the variability of the spectrum of wind direction and buoy orientation. A long-term comparison of wind direction with three neighboring measurement stations in Italy will also be presented. In the discussion section, the advantages and drawbacks of the methods applied are discussed, and the results are stated. Key findings are summarized in the conclusions section.

\section{Methods}

\section{a. Measurement devices}

\section{1) Coastal Buoy Vida}

Buoy Vida (Fig. 1) was deployed in the fall of 2008 to replace its predecessor Coastal Oceanographic Station Piran (COSP; http://www.nib.si/mbp/en/oceanographicdata-and-measurements/buoy-2/general-2) and was positioned at $45^{\circ} 32^{\prime} 55.68^{\prime \prime} \mathrm{N}, 13^{\circ} 33^{\prime} 1.89^{\prime \prime} \mathrm{E}$. Its hull is $2.5 \mathrm{~m}$ in diameter, its mass is $4.38 \mathrm{t}$, and it is constructed of 5-mm stainless (inox) steel 304. It is anchored with three cylindrical concrete blocks (diameter: $1.3 \mathrm{~m}$; height: $0.5 \mathrm{~m}$ ), which have a combined mass of about 4 tons. The connecting anchoring chains are $50 \mathrm{~m}$ long and are composed of steel chain links with diameters of $36 \mathrm{~mm}$. The chains were placed $120^{\circ}$ apart around the buoy, about 20-25 $m$ away from it. An anemometer was placed on top of a mast at a height of $5 \mathrm{~m}$ above the mean sea surface; the height varies slightly $(0.5 \mathrm{~m}$ at most $)$ because of the seasonal fouling of the anchoring chains with mussels within the top half of the water column. Buoy Vida is powered by both solar panels and a fuel cell.

The brain of the system on buoy Vida is a single-board computer (Calao Systems SBC35-A9G20) with a 32-bit ARM9 microcontroller. Communicating with the system from land is based on a simple automatic repeat request (ARQ) protocol transmitted over user datagram protocol (UDP) with cyclic redundancy check (CRC) as the transmission error detection method (Šonc 2014). The system's clock is synchronized with the GPS clock every day at midnight. All data are transmitted to the land receiving station (Marine Biology Station Piran) $3.7 \mathrm{~km}$ away to the southeast through a 

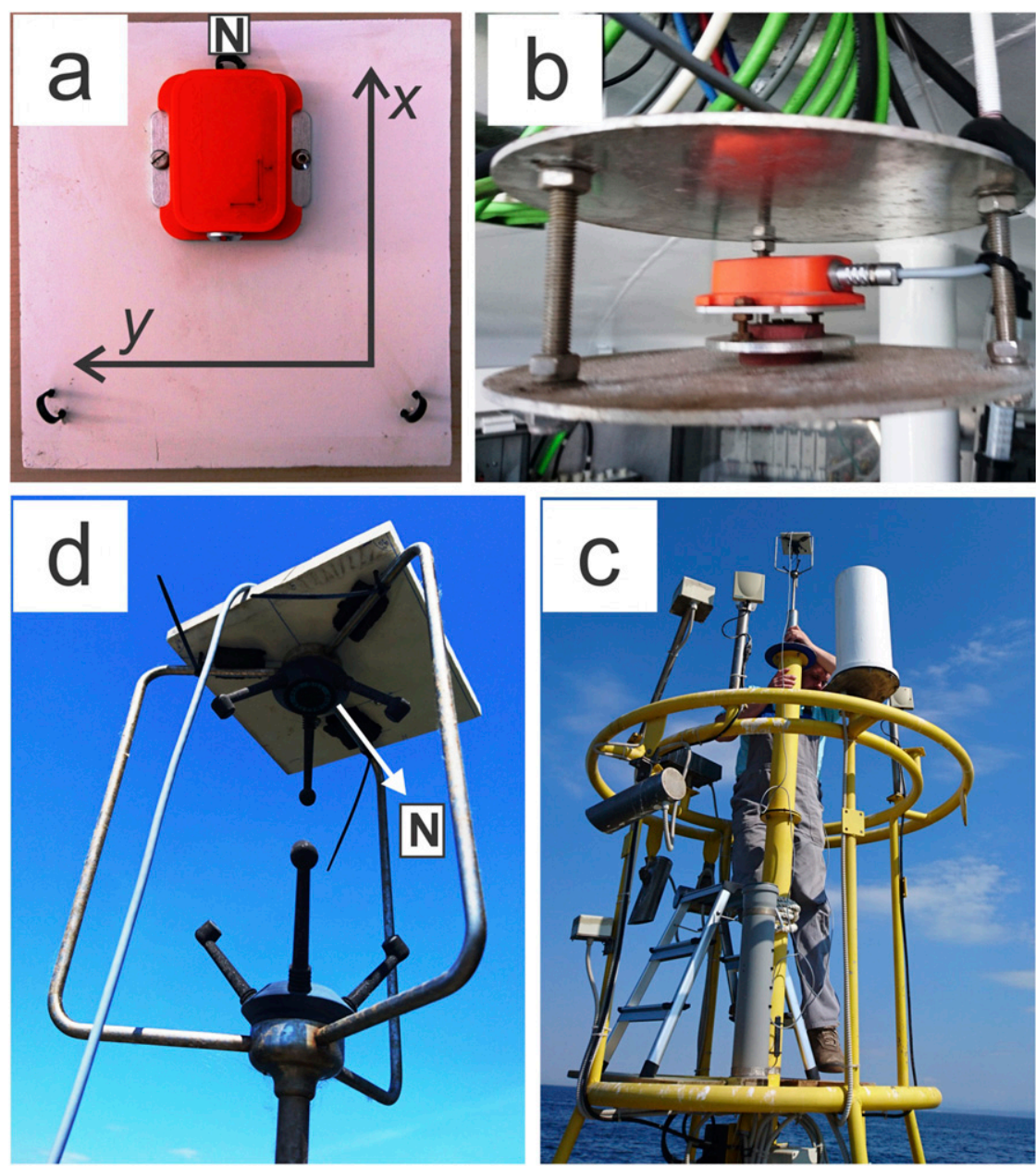

FIG. 2. (a) Top view of the MTi 3D compass/tilt unit from Xsens Technologies. Coordinate axes in the horizontal plane are depicted, where the $x$ axis is oriented north $(\mathrm{N})$ and the $y$ axis, following the right-hand orientation of the coordinate system, points west, which places the $z$ axis upward from the instrument's plane. (b) Placement of the instrument on a holding plate inside buoy Vida's hull, directly below the mast tube hole through which the cables of the atmospheric sensors enter. (c) Placement of the twin MTi compass on top of the anemometer above buoy Vida's mast. (d) Zoom of the twin MTi compass on top of the 3D WindMaster Pro anemometer from Gill Instruments.

wireless microwave link with a carrying frequency of $5.0 \mathrm{GHz}$. In case of malfunction, an emergency link with a frequency of $2.4 \mathrm{GHz}$ is activated.

Data are transmitted with different sampling periods that range from $0.1 \mathrm{~s}$ for anemometer and compass data ("raw" data), which will be described later, to $30 \mathrm{~min}$ for data retrieved from the bottom-mounted $600-\mathrm{kHz}$ Acoustic Waves and Currents (AWAC) device, Nortek AS (http://www.nib.si/mbp/images/pdf/boja_dokumentacija/ eng/Buoy_sampling_eng.pdf). All sensors measuring ambient quantities and probes have "twins," which are calibrated and ready to replace the sensors in operation. The data stream of raw $(0.1 \mathrm{~Hz})$ wind and compass data from buoy Vida is processed operationally at the land receiving station, where the data are stored and validated (with attached error codes) in a relational database. The automated quality control for wind, air temperature, and humidity measurements follow international guidelines (Intergovernmental Oceanographic Commission and Commission of the European Communities 1993).

\section{2) COMPASs/TILT DEVICE}

Buoy Vida's MTi 3D compass/tilt orientation device (Xsens Technologies) is shown in Fig. 2; its characteristics are described in the user's manual (Xsens Technologies 2008). It is a lightweight (mass: $55 \mathrm{~g}$ ) instrument enclosed in a plastic casing with an aluminum bottom plate and dimensions of $58 \mathrm{~mm} \times 60 \mathrm{~mm} \times 24 \mathrm{~mm}$ (width $\times$ length $\times$ height $)$. 
Ranges for yaw and roll are $\left[-180^{\circ}, 180^{\circ}\right]$ and for pitch is $\left[-90^{\circ}, 90^{\circ}\right]$. Its angular resolution is $0.05^{\circ}$ [root-meansquare (RMS) in a homogeneous magnetic environment], the static accuracy (roll and pitch/heading) is $<0.5 / 1.0^{\circ}$, and the dynamic accuracy is $2^{\circ}$ RMS (depending on the type of motion) with a user-settable update output rate. On buoy Vida, this setting is set to $10 \mathrm{~Hz}$, while internally, the instrument samples at a frequency of $160 \mathrm{~Hz}$ and outputs every sixteenth value. The MTi device's orientation is computed by an Xsens Kalman Filter for 3 degrees of freedom using signals from gyroscopes, accelerometers, and magnetometers. Xsens claims that a "statistical optimal 3D orientation estimate of high accuracy" is achieved in this way, with no drift for both static and dynamic movements (Xsens Technologies 2008).

The key output quantities for correcting wind measurements are the rotation/tilt angles yaw $\psi$, pitch $\theta$, and roll $\varphi$. Positive "yaw" is explained with the support of Fig. 2a. It is defined as the angle of the right-handed clockwise rotation (corkscrew rule) while looking along with the $z$ axis (positive upward), or while rotating from the $x$ axis (pointing to north) to the $y$ axis (pointing to west) for an angle $<180^{\circ}$. Statements purporting to use yaw should be regarded cautiously as it is also known as "heading," "pan," or "azimuth" (Xsens Technologies 2008 , p. 13) and since yaw, in this case, is nearly the "negative azimuth." The definitions of "pitch" and "roll" will follow in section $2 \mathrm{~b}(4)$ in a description of the rotation matrix between coordinate systems that discusses correcting the wind direction.

The MTi device also produces "calibrated data," including three orthogonal translation accelerations with a range of $[-50,50] \mathrm{m} \mathrm{s}^{-2}$, which were used to calculate the translation speed of the anemometer. The estimated acceleration error seems blurred by the multiplicity of quantities listed in the manual (Xsens Technologies 2008, p. 16) such as linearity, bias stability, scale factor stability, noise density, and alignment error. By far the largest is linearity (error), which is equal to $0.5 \%$ of FS (full scale). Thus, the acceleration error was estimated to be $\leq 3 \mathrm{~m} \mathrm{~s}^{-2}$, which seems considerable. There is also the rate of turn around three orthogonal axes. Since this study is limited to estimating the anemometer's orbital speeds, rates of turn from the MTi device were not applied; estimating them from the buoy's range of the angular tilt/rotation and typical periods of motion was sufficient.

The MTi device was placed inside the buoy's hull, just below the mast tube hole, where all the cables connecting the input-output units of the motherboard to the instruments and antennas enter (Fig. 2b). Validating the orientation of the MTi 3D compass inside buoy Vida's hull was accomplished by comparing its measurements with the direction and tilt of the anemometer. The latter is located on top of the buoy's mast (Fig. 2c), and its orientation and tilt was measured with a twin MTi 3D compass that was placed temporarily on top of the anemometer (Fig. 2d). First, the twin MTi 3D compass was fixed onto a white plate (Fig. 2a), then the plate was mounted on top of the anemometer and fixed to its three side rods (Fig. 2d shows the plate from below). The 3D compass measurements inside buoy Vida's hull were validated on 17 May 2017 in clement weather (wind $<3 \mathrm{~m} \mathrm{~s}^{-1}$ ). Once the twin MTi 3D compass was installed on top of the anemometer and connected to a notebook computer placed inside buoy Vida's hull, the MTi compass inside the hull was connected to another notebook computer. The mean misalignment for yaw was only about $-0.07^{\circ}$ after fine tuning, while the standard deviation of $0.8^{\circ}$ could not be reduced because of ripple waves at sea. Roll and pitch were at the same level as the first data sequence before the MTi was rotated, within the standard deviation of measurements. Notably, a long-term history of "drift" of the MTi device's orientation inside the buoy's hull was not required in the longterm analysis of wind direction measurements because the wind data averages of the last $10 \mathrm{~min}$ before a full hour were not corrected for the anemometer's orientation by using MTi compass data but were corrected a posteriori. Nearly 10 years of operation showed that the amount of MTi compass orientation and tilt data that were erroneous was relatively small. Thus, the MTi compass has proven to be robust and fit for the orientation needs of a coastal buoy.

A brief notation about the MTi device's response time is appropriate here. Tests of sudden changes in orientation (a stepwise function) and with sinusoidal variation of orientation show that this instrument is capable of following "true" changes of orientation, with periods of a few seconds (Šonc 2006). This quick response time is uncommon for instruments that are mostly used in navigation (sailing) and have an orientation response that is too slow and cannot adequately follow oscillations mostly caused by surface waves.

\section{3) Anemometer}

A 3D sonic anemometer, the WindMaster Pro from Gill Instruments (2010), was placed on top of the buoy's mast (Fig. 2c). The central space among six transducers (Fig. 2d) was $5 \mathrm{~m}$ above sea level. The anemometer was placed in the X1 setting, which means that the $U$ component of wind velocity was aligned to the north, the $V$ component to the west (not east), and the $W$ component (vertical) followed a right-handed coordinate system. The $W$ was therefore oriented upward along the instrument's 
axis if the anemometer stood vertically. At sea, the anemometer was usually tilted a few degrees. Its mass and size were $1.7 \mathrm{~kg}$ and $0.75 \mathrm{~m} \times 0.24 \mathrm{~m}$ (height $\times$ depth), respectively. The output data frequency was $10 \mathrm{~Hz}$ (the same as the MTi compass), while the internal sampling of wind was done at $32 \mathrm{~Hz}$ for wind speed with a range of $0-60 \mathrm{~m} \mathrm{~s}^{-1}$, resolution of $0.001 \mathrm{~m} \mathrm{~s}^{-1}$, and accuracy $\left(12 \mathrm{~m} \mathrm{~s}^{-1}\right)$ of $1.5 \%$ RMS; the direction had a range of 0 $359.9^{\circ}$, resolution of $0.10^{\circ}$, and accuracy $\left(12 \mathrm{~m} \mathrm{~s}^{-1}\right)$ to $2^{\circ}$. False or erroneous anemometer data were marked with an error status code (Gill Instruments 2010, p. 46) by the Windmaster Pro's software. It is worth noting that during harsh weather (which was usually accompanied by high electric potential in the air), the amount of false data around those measurements marked as erroneous could be much greater than the number of measurements labeled with an error status code. In those conditions, it was not easy to eliminate the erroneous data from postprocessing. The software tool for eliminating erroneous data is based on statistical properties of data and is still under development. At buoy Vida, the output sampling of the anemometer was not synchronized with the output sampling of the MTi compass. However, the sampling time discrepancy between the two instruments' outputs did not exceed $0.1 \mathrm{~s}$ and was usually much smaller.

\section{b. Analysis of wind measurements}

The relation of "true" wind speed with respect to the "apparent" wind on a moving vessel is an issue of long standing, especially in practical sailing (Marchaj 2000, 162-163), when the motion of the anemometer (float or vessel) is equal to sailing speed. In sailing, the vertical inclination of the sailing object plays no role; however, the moving anemometer on top of a floating (yet anchored) buoy cannot drift far from its position in calm weather. A much more appropriate approach to wind correction was developed for shipborne direct measurements of turbulent fluxes above the sea surface (Fujitani 1981), in which the angular motions of yaw, pitch, and roll were included in the wind measurement corrections. Later, this system of air-flux measurements was improved by using the stable platform system (Fujitani 1985). Then calculating "true wind" comprised three contributions: the transformation of three components of wind measurements to a reference coordinate system due to local tilt and rotation of the measurement coordinate system, the angular velocity of a ship's coordinates around the reference ones, and the translation speed corrected for the vessel's speed. This method was subsequently applied (Edson et al. 1998) where the three contributions were maintained, while the turbulent fluxes were calculated by two methods, one related to the stabilized platform system [already introduced by Fujitani (1985)] and the other to the "strapped-down method." In the latter, the instruments were strapped down to a main (moving) platform that was also equipped with instruments measuring the rate of angular rotation about the three axes in the platform frame.

The method for correcting wind measurements presented here will mostly focus on buoy Vida's orientation (tilt and rotation) to wind direction. Before that, however, the influence of a buoy's motion on wind speed also needs to be clarified. As previously mentioned in section 2a(2), the MTi 3D compass also outputs three orthogonal components of translation acceleration. Some caution when calculating the three translation velocity components of buoy Vida's motion (of the 3D compass device inside the buoy's hull) is appropriate.

\section{1) ANALYSIS OF SHORT-TERM WIND MEASUREMENTS}

A 4-h summer storm that lasted from 2100 UTC 19 August until 0100 UTC 20 August 2017 was chosen for the short-term analysis of winds and buoy Vida's motion. During summer storms, winds change significantly in speed and direction in a short time period (Fig. 3), making them a logical choice to explore the influence of motion and the anemometer's changed orientation on wind measurements. To retrieve the periods with a Nyquist lower limit of a period $1 \mathrm{~s}$ in spectral analysis, raw data from the compass and anemometer were averaged into 0.5 -s intervals. Thus, "seed" data were collected for $U, V$, and $W$ wind components and yaw, pitch, and roll angles, which were further averaged over 1 and $3 \mathrm{~s}$ and $15 \mathrm{~min}$. The first two averaging periods generate the data that is suitable for the estimate of wind gusts (WMO 2008), while the third one is a compromise period that demonstrates the effect of "typical" wind averaging period that spans from 5 to $30 \mathrm{~min}$. When calculating the translation velocity from the MTi device's translation accelerations, the low-frequency component of the latter must be filtered out. Therefore, the low-pass filter on 0.5-s compass acceleration data frequently used in oceanography (Alessi et al. 1985, see p. 21) seems appropriate. The code is available online (https://woodshole.er.usgs.gov/operations/sea-mat/ bobstuff-html/pl64tap.html). In this case, the filter was set up to remove high-frequency components where the half-amplitude period was $10 \mathrm{~s}$; the high-pass series of acceleration components was obtained by subtracting the filtered series from the original one. Three of buoy Vida's translation velocity components $\mathbf{V}_{b}=\left(V_{b x}, V_{b y}\right.$, $V_{b z}$ ), which were aligned with the wind velocity components $\mathbf{V}_{w}=(U, V, W)$ and pointed north, west, and 

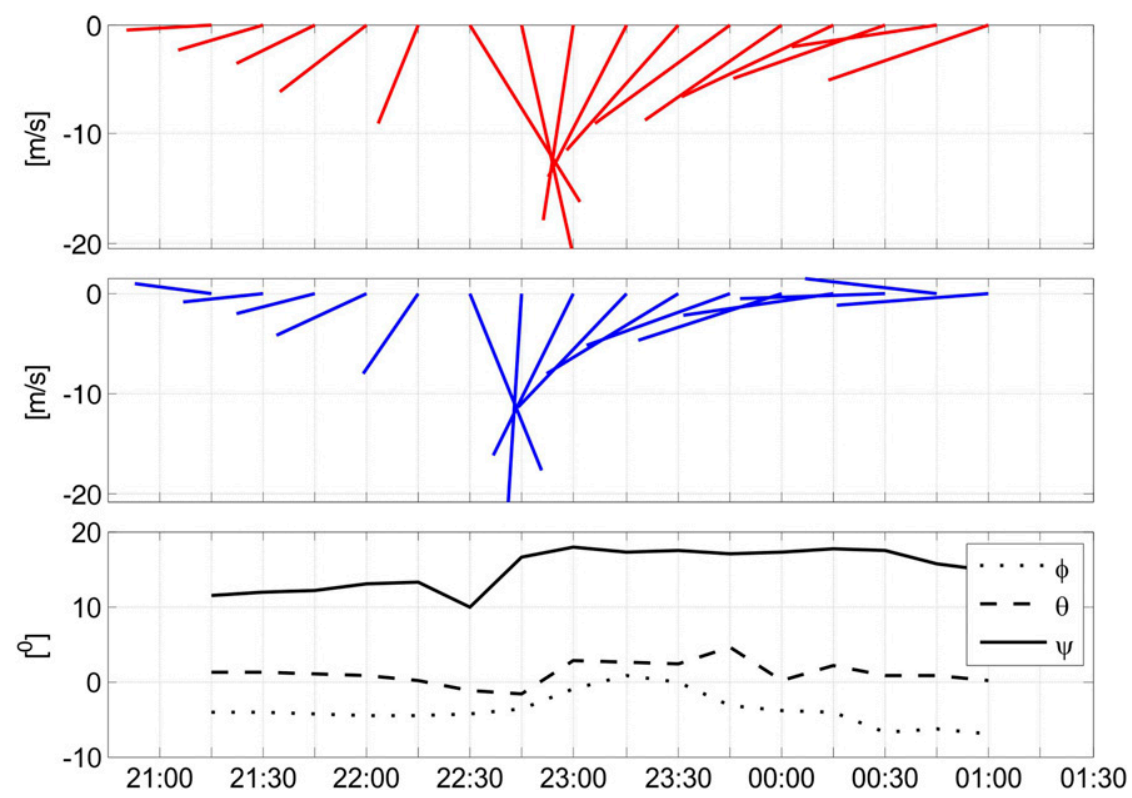

FIG. 3. Plot of the wind's evolution during a short summer storm on the night of 17-18 Aug 2017. (bottom) The 15-min averages of the yaw (full line), pitch (dashed line), and roll (dotted line). (middle) Stick plot of uncorrected 15-min interval averaged winds on buoy Vida. (top) Stick plot of corrected 15-min-interval-averaged winds on buoy Vida.

"up" (along a tilted mast), were obtained by the simple trapezoidal integration of the high-pass acceleration components. The 1- and 3-s and 15-min translation movement speeds of the buoy and wind are nonlinear functions; some attention is required. The 0.5-s translational (seed) speeds of the anemometer were calculated from the 0.5-s components $V_{b x}, V_{b y}$, and $V_{b z}$ as follows:

$$
V_{b}=\sqrt{V_{b x}^{2}+V_{b y}^{2}+V_{b z}^{2}} .
$$

Equation (1) applies to the wind speed $V_{w}$ as well. However, the 1- and 3-s and especially 15-min speeds $V_{b T}$ and $V_{w T}$, in which $T$ represents the averaging period within which the 0.5 -s seed velocities were averaged, were calculated differently:

$$
V_{b T}=\left\langle\sqrt{V_{b x}^{2}+V_{b y}^{2}+V_{b z}^{2}}\right\rangle_{T},
$$

where \langle\rangle denotes time averaging. Equation (2) means that the time averaging and vector magnitude operations are reversed with respect to Eq. (1). It can be shown that if the reversed order of operations is not done, then the 1- and 3-s and especially 15-min speeds do not follow the curves of the 0.5 -s speeds in a meaningful sense. For clarity about the effect of buoy motion on wind speeds, only the 0.5 -s and 15 -min speeds will be presented in the results and discussion section (Fig. 4).
However, the 0.5-, 1-, and 3-s and 15-min averages of wind components will be presented (Fig. 5) along with yaw, pitch, and roll angles in a survey of the fluctuations of wind components during the storm.

The variability of the spectral composition of roll, pitch, and yaw, with wind speed, buoy speed, and acceleration is demonstrated by looking at 30-min segment intervals of the power spectrum filled with 0.5 -s data $(n=3600)$, where the 15 -min segments overlap $50 \%$ of the time. In a time span of $4 \mathrm{~h}$, there are $N=28800$ instances of 0.5 -s data and $k=2(N / n)-1=15$ number of segments. The segment window is a Hamming one (Press et al. 1992), with a sampling frequency of $f_{S}=$ $2 \mathrm{~Hz}$. A MATLAB spectrogram function was applied for spectra of all quantities (https://ch.mathworks.com/ products/new_products/latest_features.html). All power spectra $\left(p_{s}\right)$ values were transformed into log form as $10 \log _{10}\left(p_{s}\right)$.

\section{2) ANALYSIS OF LONG-TERM WIND MEASUREMENTS}

Buoy Vida's wind direction measurements were validated with wind direction measurements from two other stations situated in the Gulf of Trieste (offshore Paloma and shoreline Molo Fratelli Bandiera) and a third (Acqua Alta tower) located $16 \mathrm{~km}$ offshore of the main entrance to the Venice lagoon (see Fig. 1 for locations). The Paloma pillar offshore station (Paloma) (http://www.ts.ismar.cnr.it/ node/84) is positioned at $45^{\circ} 37^{\prime} 6^{\prime \prime} \mathrm{N}, 13^{\circ} 33^{\prime} 55^{\prime \prime} \mathrm{E}$; its structure 


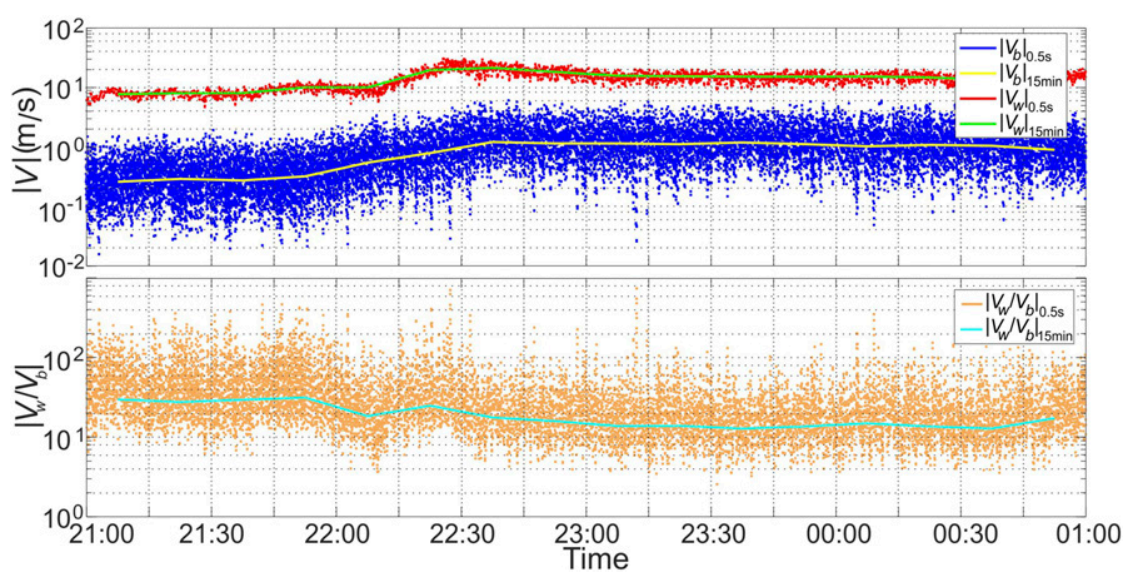

FIG. 4. (top) Wind speed averaged in 0.5-s (red dotted) and 15-min (green) intervals and 0.5-s (blue dotted) and 15-min (yellow) translation speeds of buoy/anemometer movement during the summer storm on 17-18 Aug 2017. (bottom) Ratio of wind speed vs buoy translation speed for 0.5 -s (orange dotted) and 15-min (cyan) sampling-time data.

is an elastic beacon (http://www.resinextrad.com/en/palomathe-greatest-platform-for-scientific-surveys-installed-by-cnrin-the-gulf-of-trieste/), which should not tilt more than $10^{\circ}$ sideways. It represents a hybrid between fixed- and floating-type offshore stations. The anemometer is an LSI LASTEM Compact Anemometer (DNA202), which pairs with a compact wind vane (DNA212) transducer (uncertainty of $5^{\circ}$ ), is placed $10 \mathrm{~m}$ above sea level. Data from the Paloma station yielded the wind direction for the sampling interval of the last $10 \mathrm{~min}$ before the full hour. The Molo Fratelli Bandiera shoreline station (Molo) in Trieste (http://www.ts.ismar.cnr.it/node/14) is located at $45^{\circ} 38^{\prime} 59^{\prime \prime} \mathrm{N}$, $13^{\circ} 45^{\prime} 8^{\prime \prime} \mathrm{E}$; its anemometer is a SIAP+MICROS t008 TVDV (accuracy of $2^{\circ}$ ) mounted at a height of about $10 \mathrm{~m}$. The Acqua Alta station (http://www.deos.tudelft.nl/ers/tower.html) is located at $45^{\circ} 18^{\prime} 51^{\prime \prime} \mathrm{N}, 12^{\circ} 30^{\prime} 30^{\prime \prime} \mathrm{E}$; data from an anemometer placed $17 \mathrm{~m}$ above sea level were used in the analysis. Its anemometer is a SIAP+MICROS t031 TVV wind speed and direction transducer (http:// www.siapmicros.com/prodotti/meteorologia-e-idrologia/ anemometri/t031-tvv), with the direction accuracy $2^{\circ}$, which is a pair with a wind direction transducer SIAP+MICROS t033 TDV, commissioned by the municipal tidal office of Venice (https://www.comune.venezia.it/it/ content/il-centro-maree). Hourly wind data are composed of 5-min averages of instantaneous 1-s data before the full hour.

The wind data at Vida were postprocessed following the recommendations of the WMO (WMO 2008), who suggest that the maximum speed of 3-s averages of wind speed with $50 \%$ overlap of those averaged intervals is
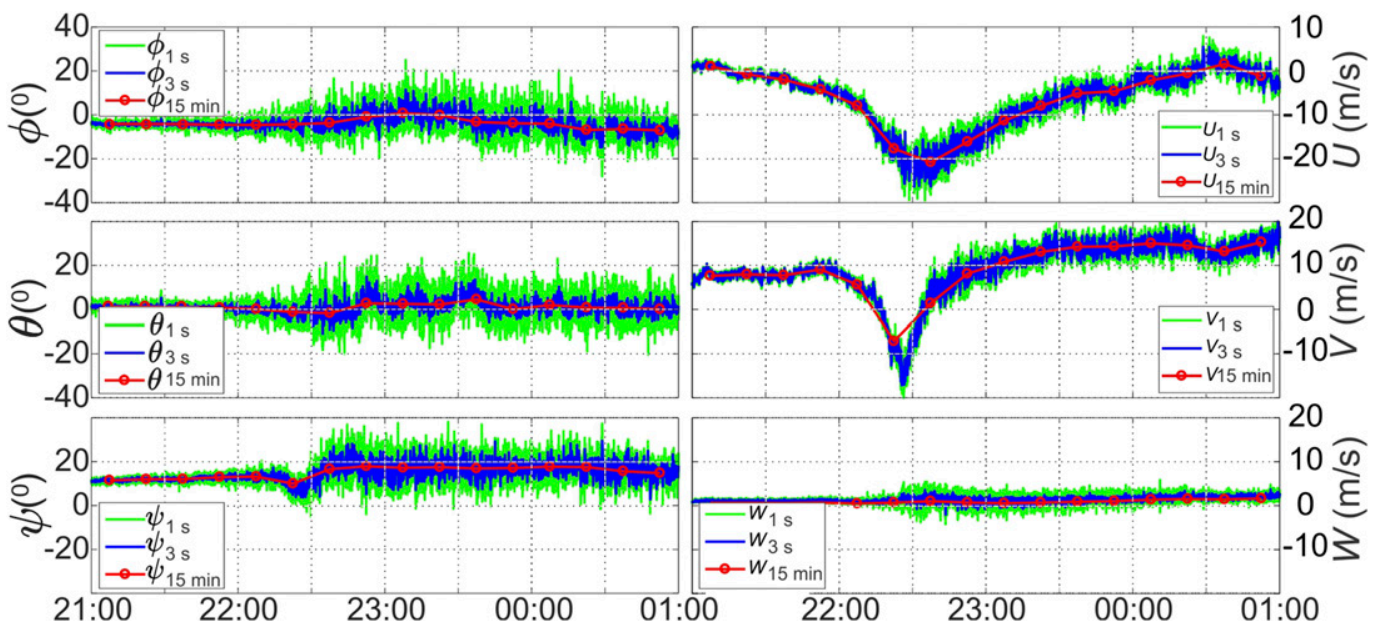

FIG. 5. (top left) Roll, (middle left) pitch, and (bottom left) yaw during the summer storm on 17-18 Aug 2017. Presented are 1-s (green), 3-s (blue), and 15-min averages (red). (top right) $U$, (middle right) $V$, and (bottom right) $W$ components of wind in the anemometer coordinate system (tilted and rotated). 
the most suitable for measuring wind gusts in an array (WMO 2008, pp. 1.5-2, 1.5-8, and 1.5-9 in particular). Another WMO manual (WMO 2014) recommends that gusts for moored buoys be determined by the "highest running mean of the record over a short time interval (e.g., 5 s)" (WMO 2014, p. 622). For buoy Vida, the 3-s averages were done operationally, with $50 \%$ overlapping (for gusts) and without overlapping for average values of 15 and $30 \mathrm{~min}$ and the 10 -min period before the end of each 30-min interval. The spectrum of buoy movement showed that 3 -s sea surface waves dominated. In the open ocean, the periods of waves can be a minimum of 2-3 times longer. Therefore, per to the recommendations, 3 -s averaging with $50 \%$ overlap was selected, and 10-, 15-, and 30-min averaging eliminated the influence of sea surface waves on the wind measurements. The same 3-s averaging was also applied to the yaw, pitch, and roll data, and the 3-s wind data were corrected operationally with the 3-s compass data to produce wind components in a referenced coordinate system north-west-up (NWU). Average values of 15 and $30 \mathrm{~min}$ and the $10-\mathrm{min}$ period before the end of the 30-min interval (along with wind gusts) were stored in a separate table of postprocessed data in a relational (MySQL) database.

Data gathered from the four wind measurement stations differed in processing (5-, 10-, or 30-min averages); therefore, a common procedure for composing wind roses was adopted that represented the wind characteristics for specific locations. Data subsampled hourly from 1 January 2009 to 31 December 2016 were applied for the wind roses. Erroneous or false negative values for direction and speed were eliminated, leaving 59666 instances of wind data from Paloma, 66678 from Molo, 69229 from Acqua Alta, and 67040 from Vida. The wind rose for Vida is twofold; it is composed of both uncorrected wind data and data corrected with the buoy's orientation, as described in the next section. The MATLAB function "wind_rose" (https://www.mathworks.com/matlabcentral/ fileexchange/17748-wind_rose) was applied using direction sectors of $10^{\circ}$ and speed intervals of $5 \mathrm{~m} \mathrm{~s}^{-1}$ to produce the wind roses.

The bora wind blowing from the ENE produced the highest speeds of all the winds, as evident in the wind roses. Therefore, the distribution of speeds on wind direction (sectors) reveals a more quantitative view of the prominent (central) wind direction's highest wind speeds. Thus, a more precise distribution of wind speed on wind direction $\alpha$ was obtained by dividing the wind directions into 60 sectors of $\Delta \alpha=6^{\circ}$, where the sector centered around $\alpha_{i}=i \Delta \alpha(i=1, \ldots, 59)$ covered directions $\Delta \alpha(i-1 / 2)<\alpha \leq \Delta \alpha(i+1 / 2)$. The zeroth sector around north, $357^{\circ}<\alpha \leq 3^{\circ}$, equals the last sixtieth sector. For speeds within sectors, the mean (average) and median values were calculated. For the average speeds within each sector, confidence limits were provided by the well-known expression $\pm t\left(\beta / 2, \nu_{i}\right) s_{i} / N_{i}^{1 / 2}$ (Thomson and Emery 2014), where $t(\beta / 2, \nu)$ is the argument in Student's $t$ distribution for $100(1-\beta) \%$ confidence and $\nu=N-1$ degrees of freedom with the number of speeds $N_{i}$ within the sector $i$ of directions. Within this sector, $s_{i}$ is the sample standard deviation of speed. In our case, a confidence level of $99 \%$ was selected. Again, for Vida, the distribution of speeds on direction is twofold: with and without correction for Vida's orientation.

\section{3) WIND DIRECTION ANALYSIS OF SAR IMAGES}

The bora wind's dominant direction was compared with wind directions deduced from satellite SAR images (RADARSAT), which represent snapshots of the surface wind field. These images reveal the spatial distribution of the bora wind over the Adriatic Sea (Lee et al. 2005; Signell et al. 2010). There are one or possibly two (parallel) jets of bora wind that commence in the eastern end of the Gulf of Trieste and end near the Venice lagoon (Signell et al. 2010). From five RADARSAT images of instantaneous snapshots of the bora wind (Signell et al. 2010, their Figs. 7a-e), the spatial "mean" direction of the jet(s) and the direction of wind vectors inside the Gulf of Trieste were graphically estimated, and the statistics of these directions will be compared with the results in this paper. More specifically, the spatial mean direction of the jet(s) inside the Gulf of Trieste, close to measurements at buoy Vida was estimated in the sense of the definition of wind directions, together with the direction of wind vectors that were posed over the distribution of wind speeds in the SAR images. Distances of jets in the Gulf of Trieste from Vida are between 1 and $13 \mathrm{~km}$, and the positions of vectors of winds in and around the gulf were at distance smaller than $24 \mathrm{~km}$ from Vida. There are no orographic barriers from the innermost (eastern) part of the gulf toward the Venice lagoon. As a result, 8 directions of jet rows and 39 directions of wind vectors were considered out from five SAR images in the estimate of bora wind direction.

\section{4) WIND DIRECTION CORRECTION}

Buoy Vida's orientation can be used to correct the wind's measured direction. As stated in section $2 b(2)$, the raw 0.1 -s data from Vida's compass and anemometer were first assembled into 3-s averages; then, data from this "sampling period" were joined to correct wind direction. These corrected 3-s wind data were used to produce averages for 15-, 30-, and 10-min period before the end of a 30-min interval. The wind direction correction is a "static" correction 
because it only includes the orientation of the anemometer without also considering the motion of the anemometer through its instantaneous rotated and tilted position.

Since an MTi compass from Xsens was used, it is logical to follow that manufacturer's definition of angles (Xsens Technologies 2016, p. 37) and angular transformation from a global $L$ coordinate system to a sensor $S$ one. Yaw $\psi$ was previously defined in description of compass/tilt device in the methods section. It is the angle of rotation around the global (reference) vertical coordinate axis $Z_{L}$, which points upward and is normal to Earth's surface (rotation matrix $\mathbf{R}_{\psi}^{Z}$ ). Pitch $\theta$ is the rotation around the $Y_{L}^{\prime}$ axis, which is the current $Y$ axis (rotation matrix $\mathbf{R}_{\theta}^{Y^{\prime}}$ ) after the first rotation (for $\psi$ around the $Z_{L}$ axis), while roll $\varphi$ is the rotation around the $X_{L}^{\prime \prime}$ axis (rotation matrix $\mathbf{R}_{\varphi}^{X^{\prime \prime}}$ ), which is the current $X$ axis after the second rotation (for $\theta$ around $Y_{L}^{\prime}$ axis). These angles are sometimes referred to as Euler angles, although other set(s) of angles have also been referred to as such (Goldstein et al. 2001, chapter 4 and appendix A). The transformation $\mathbf{R}_{S L}$ from a global (fixed) reference system to a sensor one is composed of three rotation matrices. If the " $x y z$ convention" in Goldstein et al. (2001, p. 603) is applied and their angle and matrix notations are replaced with the ones adopted here $\left(\psi_{G}=\varphi, \varphi_{G}=\psi\right.$, while $\theta_{G}=\theta, A_{G}=\mathbf{R}_{S L}$, where the subscript $G$ stands for the notations in a book; Goldstein et al. 2001), then

$$
\begin{aligned}
\mathbf{R}_{S L} & =\left(\begin{array}{ccc}
1 & 0 & 0 \\
0 & \cos \varphi & \sin \varphi \\
0 & -\sin \varphi & \cos \varphi
\end{array}\right)\left(\begin{array}{ccc}
\cos \theta & 0 & -\sin \theta \\
0 & 1 & 0 \\
\sin \theta & 0 & \cos \theta
\end{array}\right)\left(\begin{array}{ccc}
\cos \psi & \sin \psi & 0 \\
-\sin \psi & \cos \psi & 0 \\
0 & 0 & 1
\end{array}\right) \\
& =\left(\begin{array}{ccc}
\cos \theta \cos \psi & \cos \theta \sin \psi & -\sin \theta \\
\sin \varphi \sin \theta \cos \psi-\cos \varphi \sin \psi & \sin \varphi \sin \theta \sin \psi+\cos \varphi \cos \psi & \sin \varphi \cos \theta \\
\cos \varphi \sin \theta \cos \psi+\sin \varphi \sin \psi & \cos \varphi \sin \theta \sin \psi-\sin \varphi \cos \psi & \cos \varphi \cos \theta
\end{array}\right)
\end{aligned}
$$

What is needed, however, is to transform the sensor coordinate system to the global coordinate system $\mathbf{R}_{L S}$. Since $\operatorname{det}\left(\mathbf{R}_{S L}\right)=1, \mathbf{R}_{L S}=\left(\mathbf{R}_{S L}\right)^{\mathrm{T}}$, the transformation of wind components $(U, V, W)$ in the local (sensor) coordinate system to $\left(U_{N}, U_{W}, U_{Z}\right)$ (i.e., north, west, and up) components in the global coordinate system yields the following:

$$
\begin{aligned}
\left(\begin{array}{c}
U_{N} \\
U_{W} \\
U_{Z}
\end{array}\right) & =\left(\begin{array}{ccc}
\cos \psi & -\sin \psi & 0 \\
\sin \psi & \cos \psi & 0 \\
0 & 0 & 1
\end{array}\right)\left(\begin{array}{ccc}
\cos \theta & 0 & \sin \theta \\
0 & 1 & 0 \\
-\sin \theta & 0 & \cos \theta
\end{array}\right)\left(\begin{array}{ccc}
1 & 0 & 0 \\
0 & \cos \varphi & -\sin \varphi \\
0 & \sin \varphi & \cos \varphi
\end{array}\right)\left(\begin{array}{c}
U \\
V \\
W
\end{array}\right) \\
& =\left(\begin{array}{ccc}
\cos \theta \cos \psi & \sin \varphi \sin \theta \cos \psi-\cos \varphi \sin \psi & \cos \varphi \sin \theta \cos \psi+\sin \varphi \sin \psi \\
\cos \theta \sin \psi & \sin \varphi \sin \theta \sin \psi+\cos \varphi \cos \psi & \cos \varphi \sin \theta \sin \psi-\sin \varphi \cos \psi \\
-\sin \theta & \sin \varphi \cos \theta & \cos \varphi \cos \theta
\end{array}\right)\left(\begin{array}{c}
U \\
V \\
W
\end{array}\right)
\end{aligned}
$$

The three matrices from left to right in the first row of Eq. (4) are $\mathbf{R}_{\psi}^{Z}, \mathbf{R}_{\theta}^{Y \prime}$, and $\mathbf{R}_{\varphi}^{X \prime \prime}$, respectively, which agree with the matrices in Xsens Technologies (2008, p. 14, 2016, p. 38).

Wind directions at Vida were rectified by correcting them with Vida's orientation using Eq. (4). However, Vida's wind direction $\left({ }^{\circ}\right)$, without considering its orientation, can be calculated as follows:

$$
\begin{aligned}
\alpha_{r}= & 90^{\circ}+\arctan \left(\frac{U}{V}\right) \times \frac{180^{\circ}}{\pi} \\
& \begin{cases}\alpha_{r}+360^{\circ}, & \text { if } \alpha<0^{\circ} \\
\alpha_{r}-360^{\circ}, & \text { if } \alpha>360^{\circ}\end{cases}
\end{aligned}
$$

However, for the corrected wind direction $\alpha_{c}$, which considers the anemometer's orientation, the component
$U$ is replaced by the component $U_{N}$ (northern) and the component $V$ is replaced by the western component $U_{W}$, where the pair $\left(U_{N}, U_{W}\right)$ follows from Eq. (4).

Suppose that the horizontal wind components in a rotated frame $(U, V, W)$ are $(0,1,0) \mathrm{m} \mathrm{s}^{-1}$, meaning that, according to Eq. (5), the wind blows in a rotated frame from a direction (azimuth) of $90^{\circ}$. This direction of the wind, blowing from the "apparent east" results only from wind measurements. Suppose that there is no tilt $\left(\varphi=\theta=0^{\circ}\right)$ of the anemometer and that its yaw turn is $\psi=30^{\circ}$. It follows from Eq. (4) that $\left(U_{N}, U_{W}, U_{Z}\right)=$ $(-1 / 2, \sqrt{3} / 2,0) \mathrm{m} \mathrm{s}^{-1}$ and that in a fixed frame of reference, the wind blows from the direction $90^{\circ}+\operatorname{atan}\left(U_{N} /\right.$ $\left.U_{W}\right) \times 180^{\circ} / \pi=60^{\circ}$ or from the east-northeast, which is the direction of the bora wind. 
TABLE 1. Mean and fluctuating speeds of buoy velocity $\mathbf{V}_{b}$ and wind speed $\mathbf{V}_{w}$ during a storm that lasted from 2100 UTC 19 Aug until 0100 UTC 20 Aug 2017. Here, $\mathbf{V}_{b}^{\prime}=V_{b_{0.5 \mathrm{~s}}}-V_{b_{15 \min }}$, $\mathbf{V}_{w}^{\prime}=V_{w_{0.5 \mathrm{~s}}}-V_{w_{15 \min }},\left|\mathbf{V}_{b}\right|=V_{b}$, and $\left|\mathbf{V}_{w}\right|=V_{w}$.

\begin{tabular}{lccc}
\hline \hline & $2100-2200$ & $2200-2230$ & $2230-0100$ \\
\hline$\left\langle V_{b}\right\rangle\left(\mathrm{m} \mathrm{s}^{-1}\right)$ & 0.29 & 0.67 & 1.10 \\
$\left\langle V_{w}\right\rangle\left(\mathrm{m} \mathrm{s}^{-1}\right)$ & 8.50 & 14.87 & 16.10 \\
$\operatorname{STD}\left(V_{b}^{\prime}\right)\left(\mathrm{m} \mathrm{s}^{-1}\right)$ & 0.16 & 0.38 & 0.50 \\
$\operatorname{STD}\left(V_{w}^{\prime}\right)\left(\mathrm{m} \mathrm{s}^{-1}\right)$ & 1.01 & 5.87 & 2.98 \\
$\left\langle V_{b}\right\rangle /\left\langle V_{w}\right\rangle(\%)$ & 3.4 & 4.5 & 6.85 \\
$\operatorname{STD}\left(V_{b}^{\prime}\right) / \operatorname{STD}\left(V_{w}^{\prime}\right)(\%)$ & 16.1 & 6.4 & 16.7 \\
\hline
\end{tabular}

\section{Results and discussion}

\section{a. Summer storm situation}

Figure 3 presents wind variability during a 4-h storm that lasted from 2100 UTC 19 August until 0100 UTC 20 August 2017. Fifteen-minute averages of wind vectors at Vida (top two plots) are presented together with Vida's rotation (yaw) and tilt, which are composed of roll and pitch (bottom plot). The yaw $\psi$ (solid line) always had a value greater than $10^{\circ}$, and during a sharp transition of wind direction between 2230 and 2300 UTC, the yaw changed by almost an additional $10^{\circ}$. Roll $\varphi$ (dotted line) and pitch $\theta$ (dashed line), were closer to zero; they did not vary significantly during the sharp half-hour transition of wind direction. Their variability ranged over a larger period of the storm; over a span of several hours, the roll varied by about $5^{\circ}$. When wind direction was corrected according to Eq. (4), the 15-min average of raw wind direction (middle plot, blue sticks) changed to the true wind direction (top, red sticks), showing a typical end of a storm with the ENE bora wind. This storm also started with NE winds, which turned to the NW and then back to the NE. Without this correction, an observer might be left with the impression that the storm ended with an E wind or even ESE wind.

Figure 4 illustrates the evolution of buoy speeds $\left(\left|\mathbf{V}_{b}\right|=V_{b}\right)$ deduced from acceleration measurements obtained by high-pass filtering and time integration [section $2 \mathrm{~b}(1)$ ], together with the wind speed $V_{w}$ in $0.5-\mathrm{s}$ and 15-min averaging periods. The log scale on the vertical axis captures a larger span of values and emphasizes the smaller values of $V_{b}$. The storm period is divided into three sequences: 1 ) the period before the sharp turn in wind direction and increase in wind speed (2100-2200 UTC), 2) the sharp transition (22002230 UTC), and 3) the interval after the sharp transition (2230-0100 UTC). Typical speed values and fluctuations during these periods are captured in Table 1 . The value of $\left\langle V_{b}\right\rangle$ increased more than threefold, from 0.3 to $1.1 \mathrm{~m} \mathrm{~s}^{-1}$. The 15 -min wind speeds $\left\langle V_{w}\right\rangle$ increased nearly twofold, from 8.5 to $16.1 \mathrm{~m} \mathrm{~s}^{-1}$ [Eq. (1)]. The ratio of buoy speed versus wind speed ranged between $3.4 \%$ and $6.9 \%$, never surpassing $7 \%$. The fluctuating parts of the speeds were calculated from the 0.5 -s values, the standard deviation of buoy speeds $\left[\operatorname{STD}\left(V_{b}^{\prime}\right)\right]$, and the standard deviation of wind speeds $\left[\operatorname{STD}\left(V_{w}^{\prime}\right)\right]$, which increased about threefold during the storm. Their ratio reached and surpassed $16 \%$ before and after the sharp transition sequence, respectively; during the sharp transition, it was only $6.4 \%$. The numbers in Table 1 also clearly show that the ratio of standard deviation of the fluctuating part of the wind speeds versus the $15-\mathrm{min}$ mean speeds $\left[\operatorname{STD}\left(V_{w}^{\prime}\right) / V_{w}\right]$ ranged between $11.9 \%$ (first segment) and $39.4 \%$ (second segment). This ratio was much larger and steadier for the buoy's speeds; $\left[\operatorname{STD}\left(V_{b}^{\prime}\right) / V_{b}\right]$ ranged between $45.2 \%$ (third segment) and $56.7 \%$ (first segment).

Figure 5 provides a more detailed look at the wind measurements during the storm by looking at the evolution of wind components and anemometer orientation. It is clear from the 1- and 3-s averages that fluctuations in buoy orientation, as well as wind components, were much smaller before the sharp transition (until 2200 UTC) than after the sharp transition, which centered around 2215 UTC. The 15-min average did not follow the sharp transition closely for at least one $(V)$ velocity component (red line with circles in the middle-right plot), an observation also visible with a thorough look at Fig. 4 [top plot; the green line does not closely follow the fluctuations (red line) during the sharp transition segment]. Also notable in Fig. 5 is the fact that the "vertical" wind component remained around zero.

Spectral analysis of buoy Vida's angular motion (anemometer) in Fig. 6 reveals that most of the angular motion intensified around 2230 UTC and stayed enhanced until 0100 UTC (and later). The enhanced angular motion was concentrated around $0.2-0.4 \mathrm{~Hz}$ (periods between 2.5 and $5 \mathrm{~s}$ ). Yaw, the rotation around the vertical axis (right plot), also experienced lower frequencies of around $0.1 \mathrm{~Hz}$. The spectrum of wind speed (Fig. 7) resembles the spectrum of yaw to some extent, although for wind (left plot), the spectral power intensity of speed was more localized in time around the sharp transition (2230 UTC), and the frequency range around $0.3 \mathrm{~Hz}$ was slightly narrower $(0.25-0.4 \mathrm{~Hz})$. The buoy speed (center plot), however, shows a milder intensification of the spectrum, starting with the sharp transition period around frequencies between 0.5 and $0.6 \mathrm{~Hz}$, which is a consequence of the buoy's acceleration. Vida's speed was also low frequency. Acceleration, therefore, while clearly intensifying during the second storm segment, had quite randomly distributed frequencies, with some slight intensification around "wind" frequencies of $0.25 \mathrm{~Hz}$. 


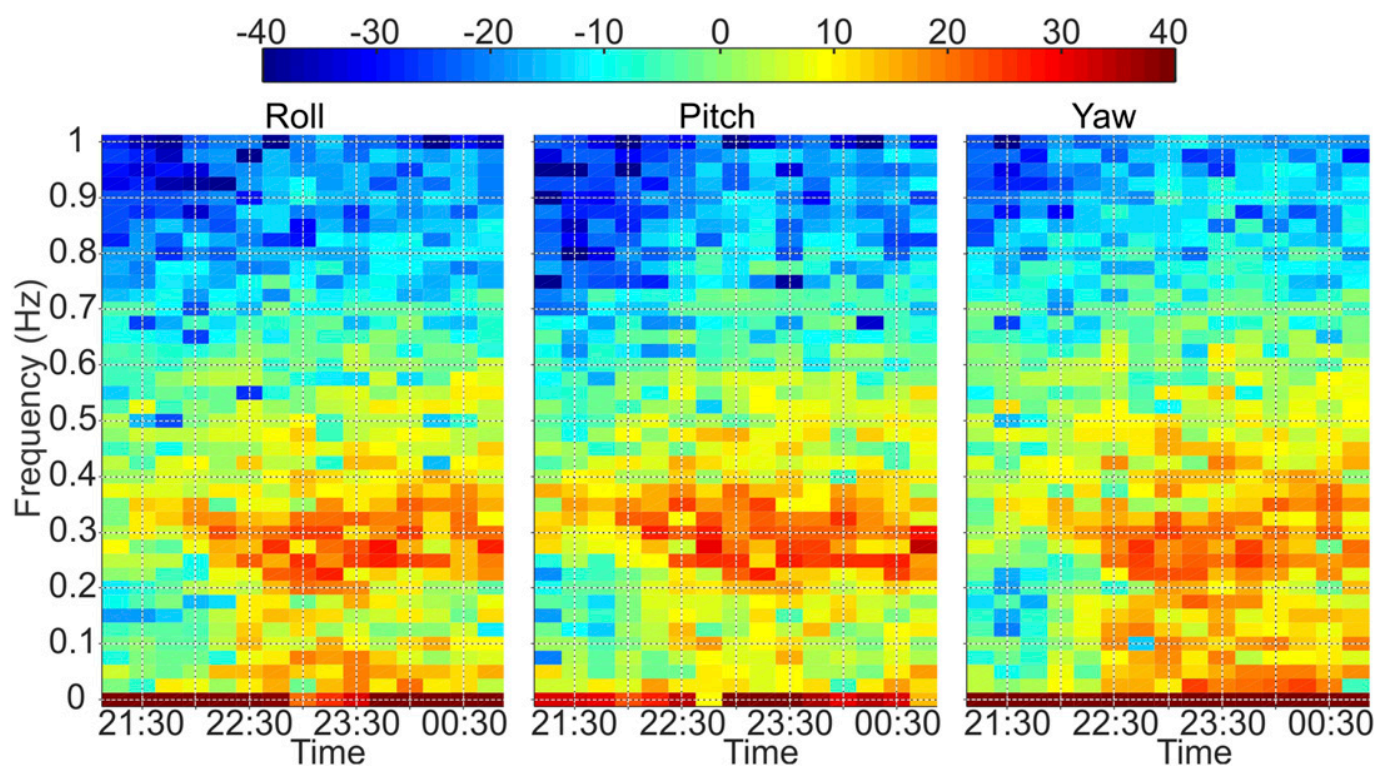

FIG. 6. Spectrum of the (left) roll, (middle) pitch, and (right) yaw angular movements of buoy Vida during the studied summer storm. The color bar refers to all plots; power spectral values are scaled as $10 \log _{10}\left(p_{s}\right)$, where $p_{s}$ is the spectrum value.

Nonetheless, acceleration and its integral (speed) matters should be interpreted cautiously.

\section{b. Long-term comparison of wind direction}

Figure 8 depicts wind roses of all four stations over the northern Adriatic Sea between 1 January 2009 and 31 December 2016. Notably, the bora wind at Acqua Alta (top-left plot) hits the area around the Venice lagoon at the directions concentrated around $40^{\circ}-60^{\circ}$. The sirocco wind, the second-most (but much less) frequent southern wind, blows from around $150^{\circ}$. On the other side of the line that connects Venice with Trieste, the wind rose is very different: at Molo station in Trieste, the bora wind peaks at $70^{\circ}-80^{\circ}$, although $50^{\circ}-70^{\circ}$ with the highest wind speeds are quite frequent. Since this station is far inside the Gulf of Trieste, the southern winds are more likely to have a more pronounced eastern component. The most frequent winds with lower speeds

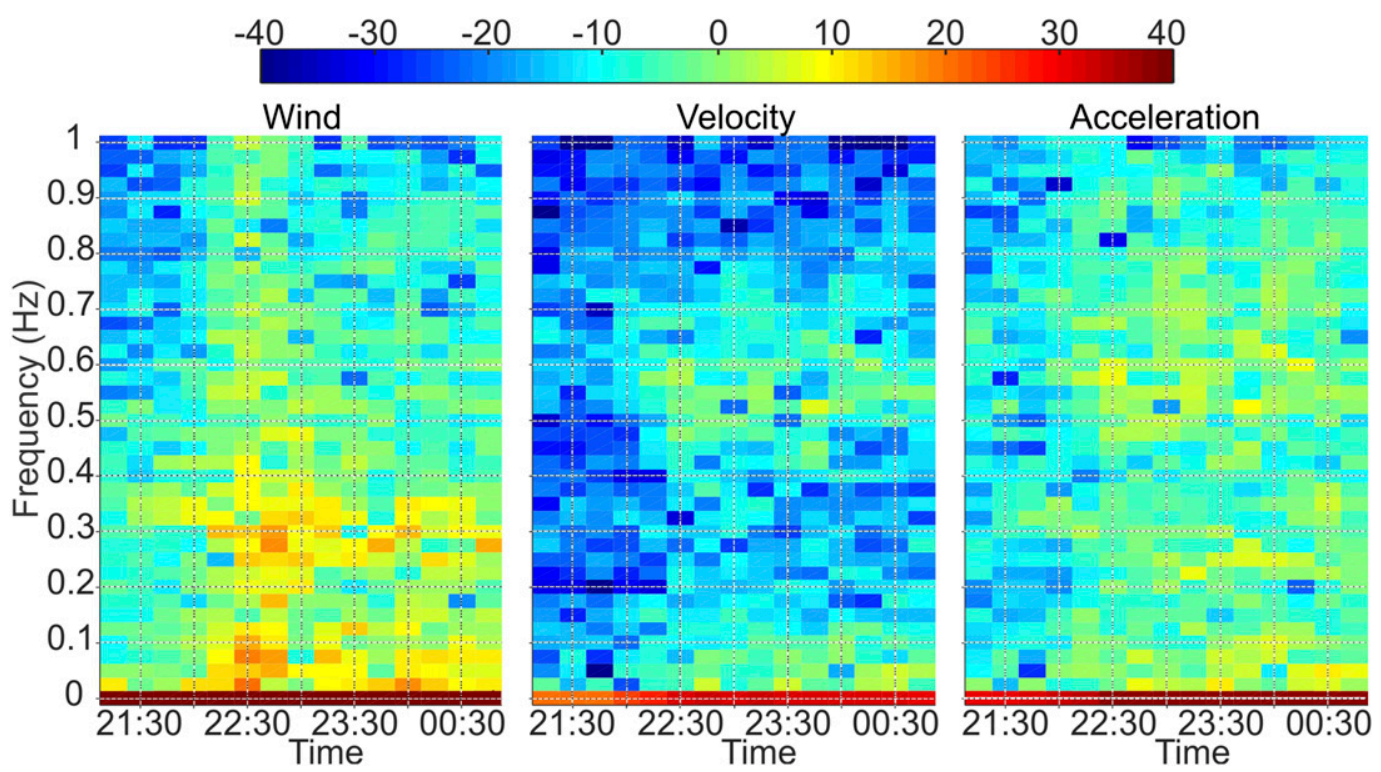

FIG. 7. As in Fig. 6, but for (left) wind speed, (middle) estimated translation speed, and (right) acceleration. 

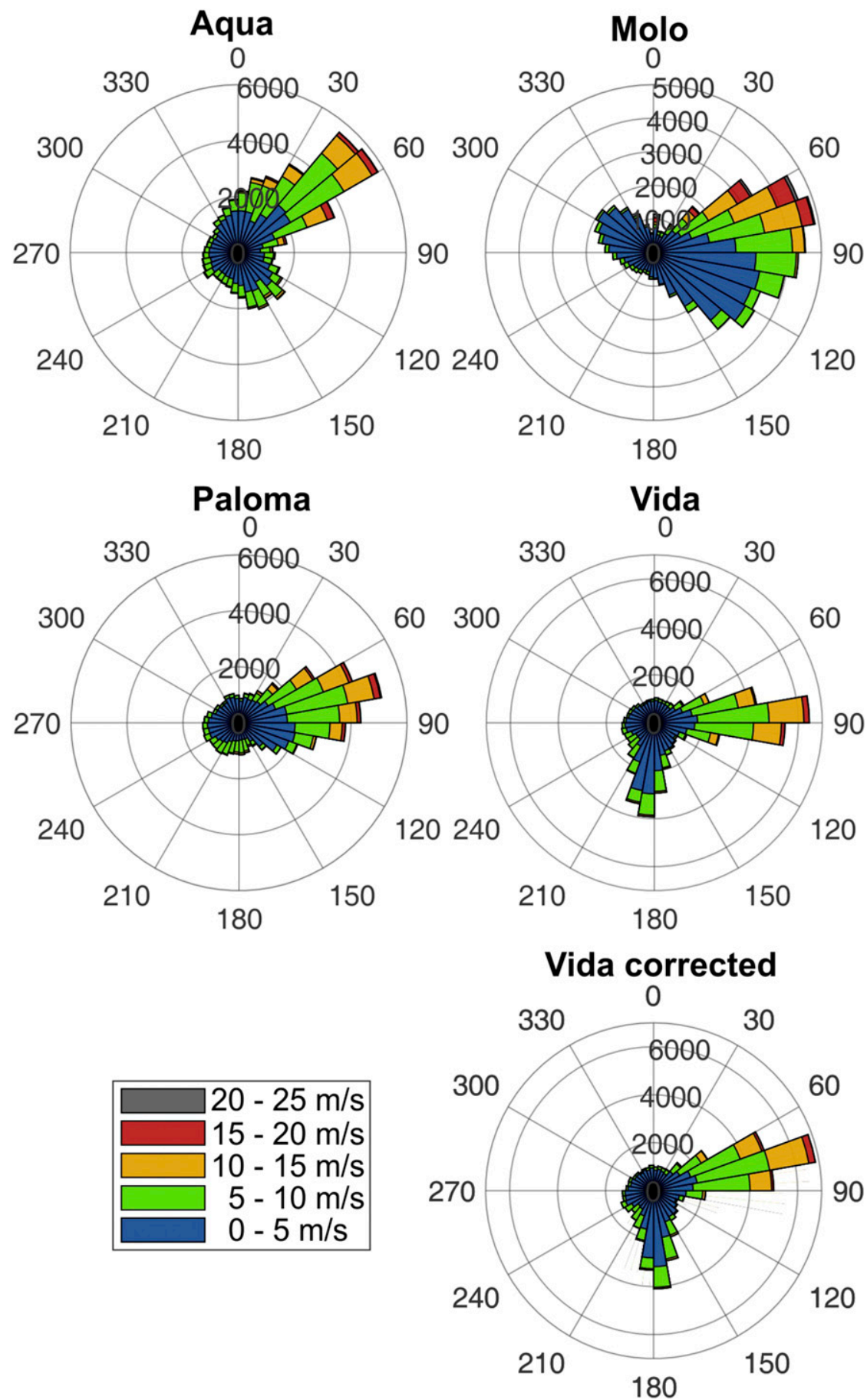

FIG. 8. Wind roses for the period between 1 Jan 2009 and 31 Dec 2016. (top left) "Offshore" station Acqua Alta tower near the Venice lagoon and (top right) onshore station Molo Bandiera in Trieste. (middle left) Pillar Paloma station and (middle right) buoy Vida in the central and southern entrance parts of the Gulf of Trieste. The wind data from Vida are uncorrected with its orientation. (bottom right) Vida with the wind direction corrected with its orientation and inclinations. Notice the similarity of the bora wind direction's peak with that of Paloma station. The numbers on the radial axes within roses denote the frequency (i.e., the number of occurrences) of winds. The legend with colors of speed ranges is applies to all roses. 


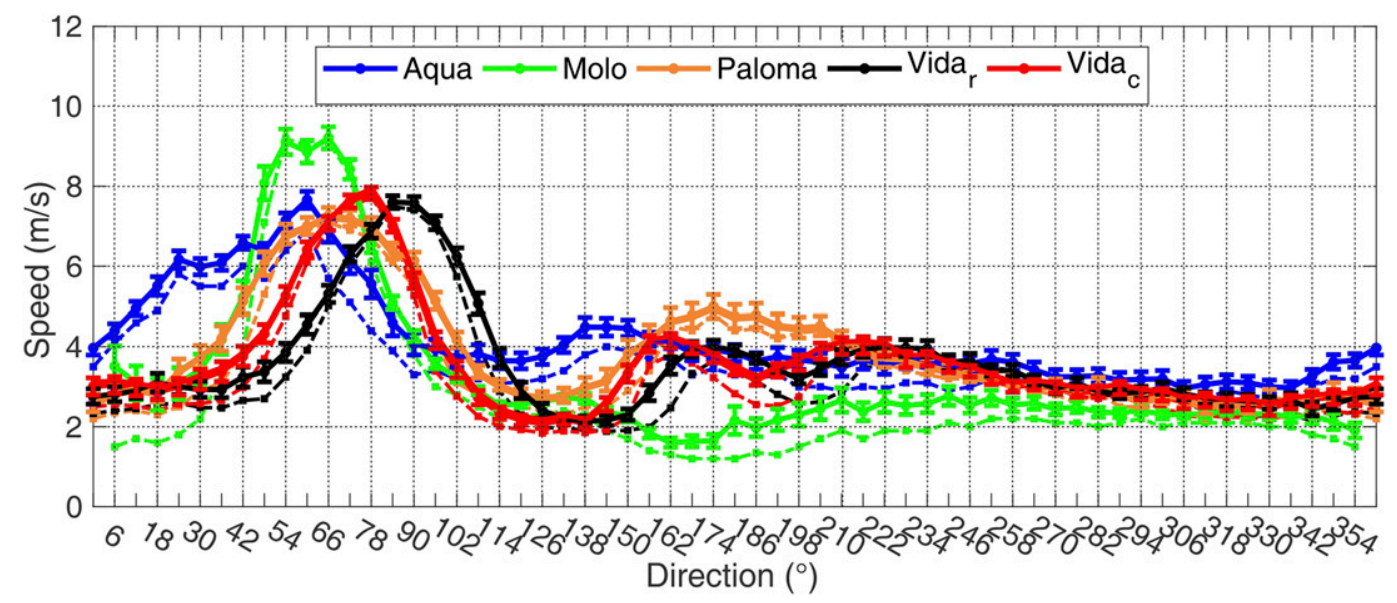

FIG. 9. Distribution of wind speed over $6^{\circ}$ sectors of wind direction at Acqua Alta station (blue), Molo (green), Paloma (orange), and Vida station (black: uncorrected or "raw"; red: corrected with Vida's orientation and inclinations) for the period from 1 Jan 2009 to 31 Dec 2016. Full lines connect average values, with vertical bars showing the $99 \%$ confidence intervals. Dashed lines connect median values (dots). Note that the peak of speeds at Vida with corrected directions (red) resides well within the broader peak of speeds at nearby offshore station Paloma.

(blue) blow from $90^{\circ}$ to $130^{\circ}$, similar to the wind rose of the Bay of Koper (Malačič and Jeromel 2008), which neighbors (the port of) Trieste. Directions of southern wind nearly blend with those of the bora; this blending is even more apparent for the weak daily sea breeze blowing from the land side. The third-most frequent group of (weak) winds blow from the WNW; they represent the daily sea breeze blowing toward Trieste from the sea. The bora wind directions in the middle of the Gulf of Trieste at Paloma station (middle-left plot), peaking around $70^{\circ}-80^{\circ}$, are similar to those at station Molo. The "southern" winds at Paloma also acquire more eastwardly directions and are therefore close to the directions of the bora. This observation looks plausible because weak winds (blue) at Paloma are also more frequent between $90^{\circ}$ and $120^{\circ}$. The wind rose at Vida for winds that are uncorrected with the orientation of the buoy (middle right plot), however, "stands out" from the point of view of wind direction: the "bora wind directions" are concentrated around the east $\left(80^{\circ}-110^{\circ}\right)$, while the sirocco southern wind that is otherwise blowing along the axis of the Adriatic, shown in the wind rose for Acqua Alta, is concentrated at Vida around $180^{\circ}$ $\left(170^{\circ}-200^{\circ}\right)$. A much better match with the other three stations for wind directions occurs when the winds are corrected with the buoy's orientation (bottom right plot); then the bora wind directions are between $60^{\circ}$ and $90^{\circ}$, with a peak between $70^{\circ}$ and $80^{\circ}$, where the strongest speed winds are also present. The southern sirocco winds are also shifted counterclockwise by $10^{\circ}$, peaking $170^{\circ}-180^{\circ}$.

Figure 9 illustrates another effect of correcting wind directions using buoy orientation. While the width of the direction sectors in the wind roses is $10^{\circ}$, the mean and median speeds are distributed over $6^{\circ}$-wide sectors. The highest peaks of the mean (full line) and median (dashed line) speeds occur at the shoreline station Molo in Trieste (green lines) that spans between $42^{\circ}$ and $78^{\circ}$. In the narrow northern sector $357^{\circ}-3^{\circ}$ of directions, the wind data at the station Molo (10-min averages before the full hour) included extremely high winds that were comparable in speed to bora winds. These rare outliers affect the average value of speed in this sector, while the median value remains reasonably low. Inspection of wind data revealed that winds with speed $>10 \mathrm{~m} \mathrm{~s}^{-1}$ in this sector were present only in the interval of directions $0^{\circ}-3^{\circ}$, while they were missing in the interval $357^{\circ}-0^{\circ}$. This indicates (very rare) occasional malfunctioning of the instrument. Moreover, this strange data were mostly packed in the time interval 29 January-12 February 2012, when extreme bora wind was experienced (Raicich et al. 2013), although other shorter time intervals were also present (e.g., 20-22 October 2012, 23-24 November 2011). A previous wind rose for this station (Crisciani et al. 1995) does not reveal high speeds in this northern sector. Therefore, we removed the unreliable values in Fig. 9 in the solid green line at the leftmost and the rightmost side of it, while the wind rose (Fig. 8) was not affected with rare outliers in the northern sector.

Otherwise, the variability of speed based on orientation follows the reasoning around the wind roses. What is clearer, however, is that when the wind directions at Vida are corrected with the buoy's orientation, the peak of bora wind speeds at Vida (red) is within the broader peak of speeds at Paloma (orange). If the wind directions 
at Vida are uncorrected (black line), the peak of (bora) speeds shifted by about $12^{\circ}$ to higher (eastern) directional values and stands out of the group of peaks of the other three stations. It is also logical to highlight that at higher wind speeds, the median speeds meet the average ones at three of the stations. The exception is the Acqua Alta station; the reason for which is yet not clear, perhaps it is related to the relatively short averaging interval of instantaneous measurement values. Otherwise, the median values are always lower than the average ones. The width of the $99 \%$ confidence level for wind speed is always small enough (more than an order of magnitude less than average values) because of the relatively high number of (hourly) measurement values. The extended time interval of 8 years therefore "pays off," and the presented statistics are sufficiently reliable.

The bora wind blowing from the ENE direction is therefore dominant at all four stations. If the wind direction is not corrected with the orientation of the buoy, the measurements at Vida will offer false wind directions; the rotation $\psi$ of the buoy around the vertical axis (yaw) decreases the wind direction by around $-11^{\circ} \pm 6^{\circ}$ $\left(-11.1^{\circ}\right.$ is the mean change in direction, $-11.6^{\circ}$ the median, $5.9^{\circ}$ is the standard deviation), calculated out of 67040 data pairs of corrected and uncorrected wind directions.

\section{c. Discussion}

Few studies have examined how the movement of an anchored floating body carrying an anemometer influences wind measurements. One reason might be the properties of mechanical anemometers, which are still commonly employed on anchored buoys. Mechanical anemometers need time to adapt to wind speed and direction because of the "inertia" of a cup anemometer and wind vane (WMO 2014, 1061-1062). The response times may be longer than the periods of motion for smaller floating devices, which wobble at sea mostly because of waves but also because of wind gusts. The effect of the anemometer's motion on wind direction is described here, when the yaw, pitch, and roll angles of the anemometer's motion are known. A coastal buoy acts as a solid body; therefore, six degrees of motion matter: three orthogonal translation components (measured by accelerometers) and three angular ones (measured by gyro sensors). Both the accelerometers and gyro instruments are integrated into the low-cost MTi compass device from Xsens. These measurements, however, should be used cautiously, especially when calculating translation and angular speeds. For example, computing translation speeds requires proper high-pass filtering, and one may easily get erroneous (huge) speeds when acceleration components are integrated.
"True" and apparent wind speed in maritime and sailing applications are calculable (Bethwaite 2009; Marchaj 2000). However, as noted in the analysis of winds (section $2 b)$, the influence of motion on anemometer orientation is best accounted for in field measurements of atmospheric turbulence or "flux measurements" (Edson et al. 1998; Fujitani 1981, 1985). Horizontal velocity components also result from the latter, and the anemometer's velocity on a floating device is composed of all of them.

Translation velocity was estimated by roughly integrating the accelerometer data with the trapezoidal method. Among the three contributions to wind measurements, two have been considered here (the orientation of the anemometer and its speed). A brief estimate of the third contributor, the influence of an anemometer's angular (orbital) velocities, can be given here. The anemometer is positioned $5 \mathrm{~m}$ above sea level, and the center of gravity and metacenter cannot be more than $2.7 \mathrm{~m}$ below the water level because that is the maximum depth of the sunken part of the buoy. For simplicity, a radius of orbital motion $r=7 \mathrm{~m}$ was chosen to obtain a conservative estimate. The most frequent period of motion was $T=3 \mathrm{~s}$ (see Fig. 6), and the maximum period of waves measured over a $10-\mathrm{yr}$ period never reached $5 \mathrm{~s}(4.7 \mathrm{~s}$ maximum; https://www.nib.si/mbp/en/oceanographic-dataand-measurements/buoy-2/extreme-values-2). The amplitude speed of orbital oscillation is reached when the buoy is at its neutral (mean) tilt, not at an extreme one. We estimated (see Fig. 5) that the buoy's typical maximum inclination $\theta_{0}$ under a storm is $10^{\circ}$ (3-s-average values) and $20^{\circ}$ (1-s-average values). These values yield a maximum orbital speed $\left(v_{0}=2 \pi r \theta_{0} / T\right)$ between $1.5 \mathrm{~m} \mathrm{~s}^{-1}$ $\left(T=5 \mathrm{~s}, \theta_{0}=10^{\circ}\right)$ and $5.1 \mathrm{~m} \mathrm{~s}^{-1}\left(T=3 \mathrm{~s}, \theta_{0}=20^{\circ}\right)$. These values are about 5 times larger than $\left\langle V_{b}\right\rangle$, the 15-min average translation speed [Eq. (1)]. However, these estimates of the amplitude of orbital oscillation speeds of a few seconds happen instantaneously and are most certainly averaged out when wind speeds of 10, 15, and $30 \mathrm{~min}$ are calculated; they seriously influence fluctuations of wind measurements, and future measurements of winds should involve more precise equipment for parallel measurements of a buoy's motion. Spectral analysis of the measured wind speeds with oscillating periods of 3-4s (Fig. 7), which dominated during the studied storm, are most certainly composed of both contributions to anemometer motion: translation and orbital speeds.

Wind measurement error cannot be deduced solely from buoy and wind speeds (e.g., the velocity magnitude). The "steady" drift of a buoy usually takes a direction in between that of winds and waves with surface currents. While the former is induced by the wind force on the hull above sea level, the latter forces the sunken part of the buoy into motion. The drift of a buoy that 
results in effective motion away from its neutral position can last only until the anchor chain(s) are strained; they prevent further translation of the buoy. The maximum possible distance away from the neutral position of a buoy with anchored chains $50 \mathrm{~m}$ long in a water column $22 \mathrm{~m}$ deep is less than $45 \mathrm{~m}$. If a typical current speed of $0.1 \mathrm{~m} \mathrm{~s}^{-1}$ under mild weather conditions is assumed, the buoy achieves a steady new mean position within $450 \mathrm{~s}=$ $7.5 \mathrm{~min}$. The drag force of winds, waves, and surface currents are likely to decrease this time by a factor of 5 because typical speeds in a storm with winds of $15 \mathrm{~m} \mathrm{~s}^{-1}$ are around $0.5 \mathrm{~m} \mathrm{~s}^{-1}$. These conditions mean that after a steady wind starts to blow, the mean speed of the buoy matters only for a time interval of around $5 \mathrm{~min}$, after which the waves and wind gusts contribute only to fluctuations of (apparent) wind measurements. The error in estimating the wind speed not considering the translation motion of the buoy during a storm is smaller than 7\% [Eq. (1)]. Thus, it is reasonable to estimate that due to the vector summation of $\mathbf{V}_{b}$ and $\mathbf{V}_{w}$, the wind speed estimation error did not reach $5 \%$.

The wind rose presented in Fig. 8 manifests the longterm effect of correcting wind directions with a buoy's orientation. The data generated by long-term analysis of measurements from Acqua Alta, Paloma, and from Vida concur with previous publications analyzing the winds along the northernmost edge of the Adriatic Sea (Jeromel et al. 2009) over a much shorter time interval (only a few years). In the years 2001-04, there was a COSP buoy at the location of Vida with a much simpler system of buoy orientation; it was composed only of azimuth. This previous system, which was otherwise suitable for the orientation of yachts and larger vessels, had a too-long response time. Such a system makes sense for vessels; if the values of vessel orientation fluctuate too much with waves, the orientation data confuse skippers instead of helping them. Data from more precise orientation devices, however, need more attention about how to make of wind direction corrections. For wind measurements, however, the response time of the orientation device should be smaller than the response time of the anemometer.

The wind rose at Trieste was previously published by Crisciani et al. (1995), who referred to a nearby location of the institute at that time, a few hundred meters away from the Molo Bandiera station placed on the shoreline. Wind roses from nearby locations in Trieste are very similar.

Satellite (SAR) images (Lee et al. 2005) of a bora wind event over the northern Adriatic Sea and analysis of the bora wind over the Adriatic Sea (Dorman et al. 2007) show that the most frequent bora wind is quite homogeneous along the line from Trieste to Venice. Bora wind directions may be further explored by analyzing the SAR images of the instantaneous wind field (Signell et al.
2010, their Figs. 7a-e). It was already apparent in that publication that two parallel jets of bora wind may commence around Trieste and extend toward the Venice lagoon. Figure 10 combines four of the five SAR images from Fig. 7 from the work of Signell et al. (2010). In the upper-left corner of each image, the directions of the jets (orange) and wind vectors (red) are copied from the marked rectangle area of the Gulf of Trieste. Out from 8 directions of jet rows and 39 directions of wind vectors, the combined (spatial) average direction is $64^{\circ}$, which is within $0.5^{\circ}$ of their median value, and the spatial standard deviation of the directions is $7^{\circ}$. We may put these numbers next to the direction of bora measurements at Vida, when the winds are corrected with the buoy's orientation: the bora wind directions peak between $70^{\circ}-80^{\circ}$ (Fig. 8), while when "bora" winds at Vida are not corrected with the orientation of buoy, then the wind directions are concentrated around the east at $80^{\circ}-90^{\circ}$. An even clearer picture is obtained from the distribution of mean and median speeds over $6^{\circ}$-wide sectors (Fig. 9): when the wind directions at Vida are corrected with the buoy's orientation, the peak of bora wind speeds at Vida (red) is placed at $78^{\circ}$. The uncorrected wind directions at Vida, move the peak of (bora) speeds to the direction about $90^{\circ}$. The bora wind direction when directions at Vida are corrected with the buoy's orientation of $70^{\circ}-80^{\circ}$ (with the width of direction sectors $=10^{\circ}$ ) and $78^{\circ}$ (with the width $=$ $6^{\circ}$ ) matches the average direction $64^{\circ}$ obtained from the SAR images much better than the direction when the correction is not included $\left(80^{\circ}-90^{\circ}\right.$ with sectors $=10^{\circ}$ and $90^{\circ}$ with sectors $=6^{\circ}$ ). Signell et al. (2010) do not explain, however, why there are also situations with relatively high discrepancies between the directions of the wind rows and wind vectors, which may surpass $30^{\circ}$, with directional wind vectors as low as $36^{\circ}$ in the inner side of the Gulf of Trieste. The comparison of measured wind directions on (floating) stations during southern (the second most frequent) winds with instantaneous wind directions deduced from SAR images is missing in this study-SAR images during southern winds were obviously "less important" in the past.

It is important to note that the direction of the axis of the Gulf of Trieste (azimuth) is $70^{\circ}$ and parallels the water border line between Slovenia and Italy, which is equidistant to points along the northern and southern coastline of the gulf. The directional range of the bora wind measured at offshore stations Vida and Paloma in the Gulf of Trieste $\left(70^{\circ}-80^{\circ}\right.$, broader range $\left.=60^{\circ}-90^{\circ}\right)$ fits well with the reasoning that inside the gulf, the bora wind blows along its axis. The direction of the bora winds estimated from the data at Vida without correcting the winds with the orientation of the buoy, however, falls outside the range of directions estimated from satellite images and the direction of the axis of the gulf. 

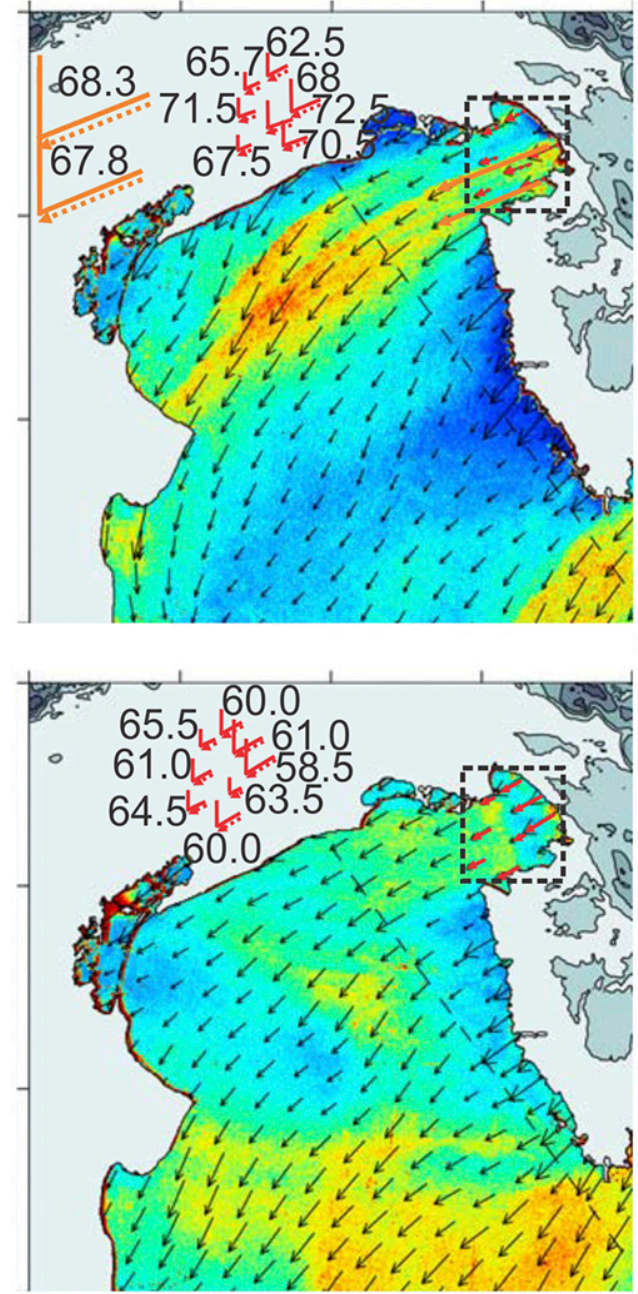

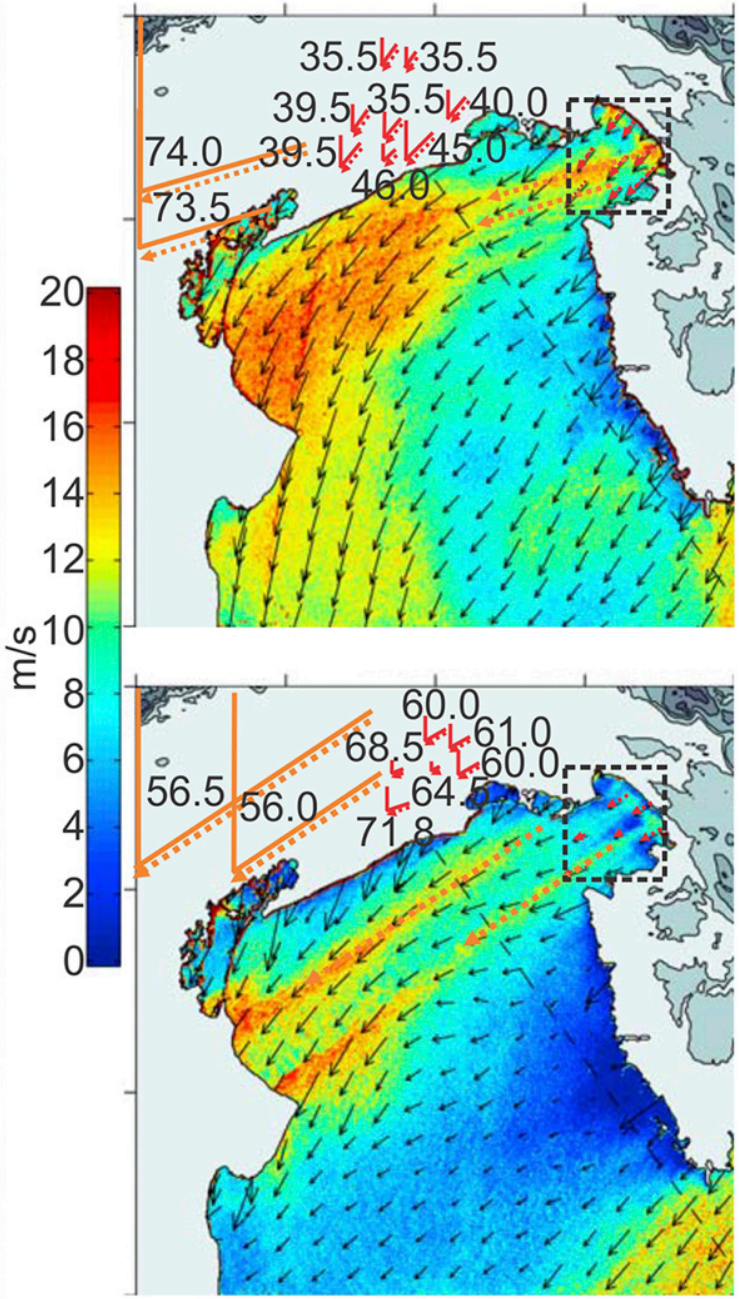

FIG. 10. SAR-derived snapshots of the bora wind field (Signell et al. 2010, their Figs. 7a-d). The focus is on jet directions (dashed lines with arrows) with higher speed (yellow color) and vectors of winds (red), which were synthesized from SAR data inside the Gulf of Trieste (dashed black frame); values of the directions are placed next to the copied vectors inside the top-left edge of each image. Only four out of five snapshots used for the directional analysis are presented here. Bora at (top left) 0515 UTC 26 Jan, (top right) 0511 UTC 2 Feb, (bottom left) 0507 UTC 9 Feb, and (bottom right) 0521 UTC 12 Feb 2003. The color bar represents wind speed. The original Fig. 7 in Signell et al. (2010) is offered with permission of the Amer. Geophys. Union.

Finally, it should be noted that if yaw orientation is applied in a transformational matrix carelessly (i.e., assuming yaw equals the azimuth), the "correction" of wind direction with buoy orientation may lead to a wind direction at buoy Vida that is inaccurate by greater than $20^{\circ}$. If this discrepancy is also present between the orientation of the anemometer and the MTi compass inside the buoy's hull, an additional $10^{\circ}$ could be added to the erroneous wind direction.

\section{Summary and conclusions}

This paper offers a method for rectifying wind direction with the orientation of an anemometer placed on a floating device. Short-term analysis of a brief summer storm showed a ratio between the anemometer's mean translation speed and wind speed smaller than $7 \%$. The "true" wind velocity can be expressed as a vector difference between the apparent (measured) wind velocity and the translation velocity of the anemometer; we estimate that this ratio was smaller, around $5 \%$. The spectral analysis of buoy Vida's winds and motion during a short summer storm revealed that oscillations of buoy motion (yaw, pitch, and roll) with periods of 3-4s (Fig. 6) dominated; waves appear to be the primary cause of these oscillations. In a sharp wind transition during the storm at around 2230 UTC 17 August 2017, the wind speed increased for all periods. 
Nonetheless, measured (apparent) wind speeds with oscillating periods of $3-4 \mathrm{~s}$ (Fig. 7) dominated during the storm, which shows the effect of surface waves on wind measurements. We did not conduct a thorough analysis of the anemometer's orbital motion, and the estimates of translation speeds should be used cautiously; further analysis could reveal that horizontal speeds strongly depend on low-pass filtering of acceleration components when measured with an MTi 3D compass. These issues deserve attention in a separate study.

This paper focused primarily on wind direction measurements and confirmed that yaw is the key measured quantity of a buoy's (anemometer) orientation that influences wind direction. Correcting wind direction with orientation angles (at least with yaw) seems to be necessary to estimate wind direction accurately. Correcting wind direction using 3-s averages of orientation data applied to 3-s averages of wind data seems a reasonable compromise between time-consuming online calculations and quality in (mean) wind direction data. Analysis of the wind measurements taken during a short summer storm (Fig. 3 is supportive) and a long-term comparison with other wind-measuring stations in the northern Adriatic confirmed that "mean" wind directions without considering the orientation of the anemometer can be incorrect by up to $12^{\circ}$. A long-term analysis of wind direction data revealed that a wind rose created at the position of Vida without considering the buoy's orientation would be erroneous (rotated anticlockwise) for this angle.

Acknowledgments. The author acknowledges the financial support of the Slovenian Research Agency (research core funding, P1-0237 and 630-11/2017-1) and the Slovenian Environment Agency (2551-17-500008), with special thanks to Maja Jeromel. He is also indebted to Arturo Pucillo, Alberto Villani, Mauro Trevisan Massimo Centore, and Paolo Battistutta at ARPA FVG, OSMER-Osservatorio Meteorologico Regionale, Settore Meteo del CFD di Protezione Civile FVG, Palmanova for the wind data from the Paloma pillar station. Thanks also go to Fabio Raicich at CNR-Istituto di Scienze Marine, Trieste, for the data from the Fratelli Molo station in Trieste. He is also indebted to Georg Umgiesser, Marco Bajo, and Mauro Bastianini from ISMAR, CNR, Venice, Italy, for the data from the Acqua Alta tower. Finally, the author extends thanks to collaborators Boris Petelin and Branko Cermelj and external collaborators Damjan Šonc and Damir Deželjin for their valuable support in extracting data from the database and providing valuable information.

\section{REFERENCES}

Alessi, C. A., R. C. Beardsley, R. Limeburner, and L. K. Rosenfeld, 1985: Introduction to the CODE-2 moored array and largescale data report. WHOI Tech. Rep. 38, 234 pp.

Bethwaite, F., 2009: Higher Performance Sailing: Faster Handling Techniques. Bloomsbury Publishing, $448 \mathrm{pp}$.

Bosard, L. F., and W. A. Sprigg, 1998: The Meteorological Buoy and Coastal Marine Automated Network for the United States. National Academy Press, 97 pp.

Cosoli, S., M. Ličer, M. Vodopivec, and V. Malačič, 2013: Surface circulation in the Gulf of Trieste (northern Adriatic Sea) from radar, model, and ADCP comparisons. J. Geophys. Res. Oceans, 118, 6183-6200, https://doi.org/10.1002/2013JC009261.

Crisciani, F., S. Ferraro, M. Maselli, and F. Raicich, 1995: Osservazioni meteomarine eseguite a Trieste nel trentenio 1965-1994. Consiglio Nationale delle Ricerche Istituto Sperimentale Talassografico Rep., 45 pp.

Dorman, C., and Coauthors, 2007: February 2003 marine atmospheric conditions and the bora over the northern Adriatic. J. Geophys. Res., 111, C03S03, https://doi.org/10.1029/ 2005JC003134.

Edson, J. B., A. A. Hinton, K. E. Prada, J. E. Hare, and C. W. Fairall, 1998: Direct covariance flux estimates from mobile platforms at sea. J. Atmos. Oceanic Technol., 15, 547-562, https://doi.org/ 10.1175/1520-0426(1998)015<0547:DCFEFM >2.0.CO;2.

Fujitani, T., 1981: Direct measurement of turbulent fluxes over the sea during AMTEX. Pap. Meteor. Geophys., 32, 119-134, https://doi.org/10.2467/mripapers.32.119.

, 1985: Method of turbulent flux measurement on a ship by using a stable platform system. Pap. Meteor. Geophys., 36, 157-170, https://doi.org/10.2467/mripapers.36.157.

Gill Instruments, 2010: WindMaster and WindMaster Pro Ultrasonic Anemometer: User manual. Gill Instruments Doc. MT0100P, 48 pp.

Goldstein, H., C. P. Poole, and J. L. Safko, 2001: Classical Mechanics. 3rd ed. Pearson Education Limited, 680 pp.

Intergovernmental Oceanographic Commission and Commission of the European Communities, 1993: Manual of quality control procedures for validation of oceanographic data. UNESCO Rep., 436 pp.

Jeromel, M., V. Malačič, and J. Rakovec, 2009: Weibull distribution of bora and sirocco winds in the northern Adriatic Sea. Geofizika, 26, 85-100.

Lee, C. M., and Coauthors, 2005: Northern Adriatic response to a wintertime bora wind event. Eos, Trans. Amer. Geophys. Union, 86, 157, 163, 165, https://doi.org/10.1029/2005EO160001.

Lin, H., Q. Xu, and Q. Zheng, 2008: An overview on SAR measurements of sea surface wind. Prog. Nat. Sci., 18, 913-919, https://doi.org/10.1016/j.pnsc.2008.03.008.

Malačič, V., and M. Jeromel, 2008: Cirkulacija in okoljske razmere v Koprskem zalivu in Luki Koper, fazno poročilo 1 (Circulation and environmental conditions in the Bay of Koper and the Port of Koper, phase report 1). Nacionalni Inštitut za Biologijo Rep. 105, $20 \mathrm{pp}$.

_ B. Petelin, and M. Vodopivec, 2012: Topographic control of wind-driven circulation in the northern Adriatic. J. Geophys. Res., 117, C06032, https://doi.org/10.1029/2012JC008063.

Marchaj, C. A., 2000: Areo-Hydrodynamics of Sailing. 3rd. ed. Adlard Coles Nautical, 763 pp.

Press, W. H., S. A. Teukolsky, W. T. Vetterling, and B. P. Flannery, 1992: Numerical Recipes in Fortran. 2nd ed. Cambridge University Press, 963 pp. 
Raicich, F., V. Malačič, M. Celio, D. Giaiotti, C. Cantoni, R. R. Colucci, B. Čermelj, and A. Pucillo, 2013: Extreme air-sea interactions in the Gulf of Trieste (north Adriatic) during the strong bora event in winter 2012. J. Geophys. Res. Oceans, 118, 5238-5250, https://doi.org/10.1002/jgrc.20398.

Ramšak, V., V. Malačič, M. Ličer, J. Kotnik, M. Horvat, and D. Žagar, 2013: High-resolution pollutant dispersion modelling in contaminated coastal sites. Environ. Res., 125, 103-112, https://doi.org/10.1016/j.envres.2012.12.013.

Signell, R., J. Chiggiato, J. Horstmann, J. D. Doyle, J. Pullen, and F. Askari, 2010: High-resolution mapping of bora winds in the northern Adriatic Sea using synthetic aperture radar. J. Geophys. Res., 115, C04020, https://doi.org/10.1029/2009JC005524.

Šonc, D., 2006: Sistem za zajem oceanografskih podatkov na Morski biološki postaji v Piranu: Poročilo o posodobitvi opreme na oceanografski boji (Oceanographic data acquisition system at Marine Biology Station Piran: Report on device replacement and software update on the oceanographic buoy). Nacionalni Inštitut za Biologijo Rep., 25 pp.

, 2014: Sistem za zajem oceanografskih podatkov: Uporabniški priročnik sistema na boji in sprejemnega dela (Oceanographic data acquisition system: User manual of the system on buoy and receiving system at Marine Biology Station Piran). Nacionalni Inštitut za Biologijo Rep., 63 pp.

Thomson, R. E., and W. J. Emery, 2014: Data Analysis Methods in Physical Oceanography. 3rd ed. Elsevier, $716 \mathrm{pp}$.

WMO, 2008: Guide to meteorological instruments and methods of observation. WMO Rep., 710 pp.

_ 2014: Guide to meteorological instruments and methods of observation. WMO Rep., 1128 pp.

Xsens Technologies, 2008: MTi and MTx user manual and technical documentation. Xsens Technologies Doc. MT0100P, 58 pp.

_- 2016: MTi and MTx user manual: MTi 10-series and MTi 100-series. Xsens Technologies Doc. MT0605P, 81 pp. 